\title{
EDITORIAL
}

\section{Five good reasons to read (and cite) the ERJ}

\author{
K.F. Rabe* and P.J. Sterk ${ }^{\#}$
}

$\mathbf{N}$ ow 5 years into the job and with 1 more year to go, your Editors are pleased to update you once again through an editorial that has developed into a regular column summarising the state of your Journal, our reflections on the job and the current developments. The leadership of the European Respiratory Society (ERS) has clearly recognised the relevance and impact of the European Respiratory Journal (ERJ) and the other allied society publications, which has resulted in the formulation of the first publication strategy around what we believe is the flagship publication, the ERJ. This has also helped us, as Editors, to critically review the current status of the ERJ and has allowed us to formulate our own mission and aims for the coming years.

To make a long story short: we believe the ERJ is doing very well indeed at the moment, but as our readers and critical audience, you obviously deserve to know why we are so untypically confident in this statement. At least five good reasons come to mind when we think about recent developments within the ERJ that have contributed to its wider acceptance amongst those of you who search for novel scientific information, to use it for your research and cite the papers presented, and those of you who "simply" read the ERJ to keep up to date with a rapidly evolving clinical field.

\section{FIVE?}

The first and probably most straightforward reason that editors and the editorial board would mention is the development of the ERJ impact factor. Although there are obviously several good reasons to be critical about using this indicator, which initially helped libraries to select the journals they would subscribe to, to rate the overall "quality" of a journal, it is a fact of life that this impact factor is widely used. It helps a journal to attract better manuscripts and better science, and it ranks the ERJ within an increasingly competitive environment of respiratory journals. Publication in high impact factor journals also helps grant applications and promotions in the academic setting. Whether this is justified or not, the impact factor of the ERJ has exceeded, for the first time, the magical line of five (you will have realised by now that the title of this editorial is not by chance...), matching our most positive predictions some years ago. Internationally, the

*Dept Pulmonology, Leiden University Medical Center, Leiden, and *Dept Pulmonology, Academic Medical Center, University of Amsterdam, Amsterdam, The Netherlands.

STATEMENT OF INTEREST: None declared.

CORRESPONDENCE: K.F. Rabe, Dept Pulmonology, C3-P, Leiden University Medical Center, Albinusdreef 2, P.0. Box 9600, Leiden, NL-2300 RC, The Netherlands. Fax: 31715266927. E-mail: erj@lumc.nl
ERJ now ranks third amongst specialist respiratory journals; and you can imagine what our future aspirations are...

\section{NEW FACES}

The second reason, affecting the whole of our constituency, is the further improved quality of your Journal in general. To make sure that the ERJ will continue to thrive in the future, we have recruited new editors with specific expertise and have aimed to improve the adequate presentation of the data, to ensure that the methodology of the presented studies is adequate, and to ensure that the statistical analysis and presentation is state of the art. We are very pleased that Joan Soriano and Giovanni Battista Migliori joined the editorial board in 2007. In addition, following the departure of Sue Chinn, we have reinforced our statistical team with Allan Hackshaw and Alicja Rudnicka, and are happy that Samy Suissa fulfils the role of methodological advisor to the ERJ.

\section{VISIBILITY}

The third reason we think the ERJ is definitely worth reading is related to the selection of published articles. While our editorial policy has always been to try and identify the best papers submitted to the Journal by positive selection, there is measurable evidence that the information provided in the ERJ is picked up quickly and is covered not only through citation in the scientific literature but also in the press. One objective parameter is a further increase in the so-called immediacy index that forms part of the impact factor calculation and describes how often articles are cited in the very same year they are published. Furthermore, since CEDOS and Eric Schaerlig regularly report press coverage of the ERJ, we are aware of its broad representation within the international press. Obviously, articles that are preferentially picked up by press releases are not identical to those that are highly cited, but the two taken together clearly support the overall impact and visibility of the ERJ.

\section{GUIDELINES}

The current issue of the ERJ presents the executive summary of the Global Initiative for Asthma (GINA) and this is clearly another good reason to read the Journal. Guidelines form an essential part of medical publishing these days and international societies and their journals need to contribute to the dissemination of this information. The ERJ has printed guidelines on a range of topics but it has never explicitly covered the documents from the GINA initiative. Guidelines and their development are recognised as an important activity of the ERS in general, and through the nomination of Mark Woodhead as the ERS Guideline Director this has been further formalised. For the changing world of guideline development, the formal aspects of assessing and grading evidence, their 
updating and the involvement of stakeholders are crucial elements. The ERS and the ERJ want to play a prominent role in this activity.

\section{SERIES}

Finally, the fifth reason we think you should read (and possibly cite) the ERJ lies in the broad spectrum of articles that we can offer. This obviously depends on the material that is being sent to us by our authors but this is also very much linked to our first point. An excellent journal undoubtedly attracts better science and more interesting papers and a positive selection of those 1,700 papers submitted to us annually will help the ERJ further, we hope. Along with our broad spectrum of clinical and basic science papers we have thus been able to attract more papers in the area of tuberculosis, pulmonary hypertension and, gradually, we are starting to attract more papers in pulmonary oncology. Our series will help us to position the ERJ in these areas and you will find a whole new selection of series articles and reviews in the new year that are clearly worth reading and we know are worth citing. The topics for series in 2008 are: End-stage COPD; Cell and animal studies in respiratory medicine; Lung cancer;
Pulmonary hypertension: from concept to management; Genetic and cardiovascular aspects of obstructive sleep apnoea; and MRSA and the pulmonologist.

\section{SUPPORT}

The ERJ thrives and we are happy with the way it has been growing over recent years. Obviously we owe thanks to all our reviewers, colleagues and the technical staff in Sheffield, UK. What we do not want to forget, though, is that over the years we have been helped tremendously through the personal and professional support of Archie Turnbull, the Managing Director of the ERS, who retired recently. We will miss his dedication and strategic insights and his personal support: thanks a lot, Archie!

\section{REFERENCES?}

At the end of this editorial article, you may look for references. Well, there are none. We strongly believe that the citation index, and thereby the impact factor of the Journal, is not helped by editorial self-citations. It is up to you to use and perhaps quote the European Respiratory Journal. Thanks! 